\title{
Modelos aplicados às atividades de educação em saúde
}

\author{
Models applied to the activities of health education \\ Modelos aplicados a las actividades de educación en salud
}

\section{Maria Fernanda Santos Figueiredo', João Felício Rodrigues-Neto", Maísa Tavares Souza Leite' \\ 'Universidade Estadual de Montes Claros. Departamento de Enfermagem. Montes Claros, MG \\ "Universidade Estadual de Montes Claros. Departamento de Clínica Médica. Montes Claros, MG}

Submissão: 10/11/2008

Aprovação: 10/12/2009

\section{RESUMO}

Este estudo objetivou compreender Quais os modelos educacionais têm sido aplicados às atividades de educação em saúde. Trata-se de uma revisão de literatura, sobre o tema "Modelos de Educação" e "Educação em Saúde", utilizando como referenciais livros-textos contemporâneos de especialistas da área de educação e periódicos sobre tais temas, disponíveis nas principais bases de dados. Os resultados revelaram Que o Modelo Tradicional de educação em saúde objetiva transmissão do conhecimento e experiência do educador, atribuindo uma importância suprema ao conteúdo ensinado, esperando que os educandos o absorvam sem modificações e o reproduzam fielmente. Já, o modelo dialógico compreende a educação em saúde como um processo de conscientização, mudança e transformação, caracterizada por uma filosofia emancipatória dos sujeitos.

Descritores: Educação; Educação em saúde; Aprendizagem.

\section{ABSTRACT}

This study aimed at determining which educational models have been applied to the activities health education. This is a review of literature on the topic "Models of Education" and "Health Education", using as reference contemporary books of specialists in the field of education and journals on such topics available in major databases. The results showed that the Traditional Model of health education aims to transfer the knowledge and experience of the educator, giving a paramount importance to the content taught, hoping that the students absorb unchanged and faithfully reproduce. The model based on dialogue understands the in health education as a process of awareness, change and transformation, characterized by a philosophy of emancipatory subject.

Key words: Education; Health education; Learning.

\section{RESUMEN}

Este estudio tuvo como objetivo determinar modelos educativos Que se han aplicado a las actividades de educación en salud. Es una revisión de la literatura sobre el tema “Modelos de Educación”, "Educación para la Salud”, utilizando como referencia libros contemporáneos, revistas sobre temas tales disponible en las principales bases de datos. Resultados mostraron Que Modelo Tradicional de educación para la salud tiene por objeto transferencia de experiências, conocimientos de al educador, lo Que da una importancia primordial a los contenidos enseñados, con esperanza de que estudiantes absorber la misma, la reproducción fiel. Modelo basado en el diálogo entiende la educación para la salud como proceso de sensibilización, el cambio, la transformación, Que se caracteriza por una filosofía del sujeto emancipatorio.

Descriptores: Educación; Educación en salud; Aprendizaje. 


\section{INTRODUÇÃO}

A educação deve contribuir para auto-formação do indivíduo, de modo a ensinar a assumir a condição humana, ensinar a viver e ensinar como se tornar cidadão ${ }^{(1)}$.

A civilização ocidental desenvolveu uma forma de pensar e agir Que se tornou predominante no mundo moderno, a racionalidade técnica, com grande valorização do conhecimento científico ${ }^{(2)}$.

Atribui-se uma importância suprema ao "conteúdo da matéria", esperando que os educandos o absorvam sem modificações e o reproduzam fielmente. Este modelo de educação, caracterizado pela transmissão do conhecimento e experiência do professor, é denominada de educação bancária. Conseuüentemente, o educando é passivo, tomador de notas, exímio memorizador, preferindo manejar conceitos abstratos a resolver de forma original e criadora problemas da realidade em Que vive $\mathrm{e}^{(3-4)}$. Tal concepção, bancária, caracteriza o Modelo Tradicional de Educação.

Entretanto, aprender é uma atividade que acontece no educando, sendo estimulada pelo educador. Ninguém pode aprender por outro. Ensinar não é o mesmo Que aprender, deste modo se o educando não aprender, todo o esforço para ensiná-lo estará perdido ${ }^{(3)}$.

A educação como prática da dominação, Que mantêm a ingenuidade dos educandos, pretendendo doutriná-los no sentindo de sua acomodação ao mundo da opressão, vem sendo objeto de crítica ${ }^{(4)}$.

Nesse sentido, o ato de educar já não pode ser o ato de depositar ou de narrar ou de transferir, ou de transmitir conhecimentos e valores aos educandos, mas um ato cognoscente, cedendo lugar para a educação problematizadora, Que sugere a superação da contradição educador-educandos ${ }^{(4)}$.

A educação "problematizadora" parte do princípio Que uma pessoa somente conhece bem algo Quando o transforma, sendo transformada também no processo ${ }^{(3)}$. Tal modelo de educação pode ser referido como Modelo Dialógico, por ser o diálogo seu instrumento essencial ${ }^{(4)}$.

A educação em saúde deve ser compreendida como uma proposta que tem como finalidade desenvolver no indivíduo e no grupo a capacidade de analisar de forma crítica a sua realidade, como também, de decidir ações conjuntas para resolver problemas e modificar situações, de modo a organizar e realizar a ação e de avaliá-la com espírito crítico ${ }^{(5)}$.

Apesar de estar bastante difundido entre os profissionais de saúde, o conhecimento crítico Que Questiona as intervenções baseadas, restritamente, nas dimensões biológicas dos problemas de saúde, havendo ainda um amplo reconhecimento da importância de mudanças subjetivas, sociais e ambientais para a superação destes problemas, parece Que estas discussões não estão sendo revertidas para ações práticas ${ }^{(6)}$.

Diante disso, indaga-se sobre a razão pela eual o modelo tradicional pode ainda prevalecer sobre o Modelo Dialógico durante as atividades de Educação em Saúde.

Alguns autores citam a aplicação do Modelo Tradicional nas atividades de Educação em Saúde como Moura e Souza ${ }^{(7)}$, Santos ${ }^{(5)}$, Bessen et $\mathrm{al}^{(8)}$ e outros a utilização do Modelo Dialógico como Alvim e Ferreira $^{(9)}$, Frota et $\mathrm{al}^{(10)}$ e Toledo et $\mathrm{al}^{(11)}$.

Entretanto, há uma escassez de estudos Que abordem de forma sistemática os modelos educacionais utilizados nas atividades de Educação em Saúde. O conhecimento desses modelos se faz necessário para Que as atividades de Educação em Saúde possam ser estruturadas a fim de alcançar os seus objetivos.

O objetivo desse trabalho foi realizar uma revisão de forma reflexiva da literatura sobre os modelos de Educação Tradicional e Dialógico aplicados às atividades de Educação em Saúde.

\section{METODOLOGIA}

Foi realizada uma revisão de literatura a partir das publicações disponíveis nas principais bases de dados: Bireme, Medline e Scielo, utilizando palavras-chaves "Modelos de Educação" e "Educação em Saúde", referentes ao período de 2004 a 2008. Foi ainda utilizado como referenciais livros-textos contemporâneos de especialistas da área de educação sobre tais temas. Após a pesQuisa bibliográfica, foi feita a seleção e leitura dos artigos e livros-textos, de forma reflexiva, buscando identificar concepções teóricas, vantagens e desvantagens e aplicação de cada modelo.

\section{RESULTADOS E DISCUSSÃO}

\section{Modelo Tradicional de Educação em Saúde}

O modelo tradicional de Educação em Saúde corresponde a forma de educar conceituada por Freire ${ }^{(4)}$ como educação bancária, em Que o papel do educador consiste em "encher" os educandos de conteúdos, fazendo depósitos de comunicados. Nesta visão, os homens são seres passivos, de forma Que cabe a educação adaptálos à realidade.

Neste modelo de educação, considera-se Que Quanto mais se ensina mais se sabe ${ }^{(12)}$. Tem-se o Que Morin ${ }^{(1)}$ caracteriza de uma cabeça bem cheia, em que o saber é acumulado e empilhado.

Nesta forma de educar, formam-se indivíduos medíocres, em Que não há estímulo para a criação, sendo o educador também considerado medíocre porQue não é adaptável e não busca outros conhecimentos, uma vez Que não é desafiado pelos educandos. A educação ainda permanece verticalizada, com o educador sendo considerado um ser superior Que ensina ao ignorante ${ }^{(12)}$.

Ao fazer isto, ao obstaculizar a atuação dos homens, como sujeitos de sua ação, frusta-os. Quando se sentem incapazes de usar as suas capacidades, sofrem ${ }^{(4)}$.

Historicamente, sempre houve uma tendência a estruturar as ações educativas em saúde no sentido de ampliar informações da população sobre os principais danos/agravos. Para tanto, inúmeras recomendações sobre comportamentos "certos" ou "errados" relacionados à vivência das doenças e à sua prevenção eram disseminados à população ${ }^{(13)}$, caracterizando o Modelo Tradicional de Educação em Saúde.

Os indivíduos são considerados como carentes de informação em saúde. A relação estabelecida entre educador e educando é essencialmente assimétrica, já que um detém um saber técnicocientífico, com status de verdade, enquanto o outro precisa ser devidamente informado A comunicação caracteriza-se pelo caráter informativo, na Qual o educador, assumindo uma atitude paternalista, explicita ao educando, hábitos e comportamentos saudáveis, o Que fazer e como fazer para a manutenção da saúde ${ }^{(14)}$. Não há aQuisição de conhecimento, mas a memorização do conteúdo narrado pelo educador ${ }^{(4)}$.

Há hiatos enormes entre a realidade de vida do educando e dos 
profissionais de saúde, tendo este último, em geral, dificuldades de traduzir e interpretar a realidade do primeiro ${ }^{(5)}$, visto Que não realiza uma reflexão sobre a realidade local ${ }^{(7)}$. $O$ educando vai agir de acordo com suas crenças e realidades, por isto Que, por melhor Que a prática educativa em saúde possa ser, ao não se considerar estes aspectos, pode ser uma ação esvaziada em $\mathrm{si}^{(5)}$.

Tem-se um estilo de pensamento curativista, com foco nas patologias, apresentando uma relação profissional-paciente impositiva ${ }^{(8)}$. Preconiza Que a prevenção das doenças prima pela mudança de atitudes e comportamentos individuais ${ }^{(14)}$.

Em estudo realizado com os profissionais de saúde da Estratégia Saúde da Família (ESF), Que realizam as atividades de Educação em Saúde ${ }^{(8)}$, verificou-se Que, além de centrar-se na doença, a educação em saúde, segue um modelo tradicional de imposição de conhecimentos, tratando a população de forma passiva, transmitindo conhecimentos técnicos sobre as patologias e como cuidar da saúde, desconsiderando o seu saber popular e as suas condições de vida. Muitas vezes, há culpabilização do próprio paciente por sua doença.

No modelo tradicional, os educadores são os autores e os atores do processo; os educandos, seus objetos. Os educadores modelam; os educandos são modelados. Os educadores optam; os educandos seguem a opção do educador. Os educadores atuam; os educandos têm a ilusão de oue atuam, na atuação dos invasores ${ }^{(4)}$.

Este modelo de educação objetiva fundamentalmente produzir um aumento de conhecimento nos educandos, sem preocupar-se com o indivíduo como ser integral e como membro da comunidade $^{(3)}$

A reflexão da literatura aponta Que este modelo tem como vantagem proporcionar para a população o conhecimento produzido cientificamente, com aquisição de conteúdos e ampliação de informações sobre o seu dano/agravo. Como desvantagens, têmse um relacionamento verticalizado entre educador e educando; a formação de um indivíduo passivo, mero receptor de informações, Que pode não saber aplicá-las a sua realidade, já Que esta não é considerada pelo profissional, durante as atividades de Educação em Saúde.

Considerando os princípios do Modelo tradicional de Educação em Saúde, acredita-se que o mesmo possa ser aplicado a projetos e capacitações de abrangência nacional, em Que há grupos com um alto número de participantes, Que necessitam ser sensibilizados, sem necessariamente mudança de prática.

\section{Modelo Dialógico de Educação em Saúde}

Para eue uma atividade seja geradora de aprendizagem, é necessário que a situação desafie o indivíduo, de modo Que ele tenha a necessidade de aceitar esse desafio e que isso esteja dentro de seus meios, ao preço de uma aprendizagem nova mais acessível ${ }^{(15)}$.

A transferência é definida como a capacidade de um sujeito reinvestir suas aQuisições cognitivas. Toda aprendizagem seria totalmente inútil, sem um mínimo de transferência, visto Que corresponderia a uma situação passada e não reprodutível em sua singularidade. Seria possível distinguir uma transferência banal, automática, de uma transferência problemática Que exige esforço e trabalho cognitivo, poreue mobiliza aquisições construídas em situações nitidamente diferenciadas ${ }^{(15)}$.

Os programas de ensino não têm sido feitos de forma a favorecer o debate, apesar das declarações de intenção, visto Que são sobrecarregados e induzem os educadores a privilegiar a transmissão eficaz de conhecimento em detrimento de uma construção comum em um debate ${ }^{(16)}$.

Contrariamente, á educação tradicional, a pretensão de toda educação é preparar os indivíduos para reinvestirem suas aQuisições em contextos variados, em situações de vida cotidiana ${ }^{(15)}$.

No modelo dialógico de educação, a solução de problemas implica na participação ativa e no diálogo constante entre educandos e educadores. A aprendizagem deve ser idealizada como resposta natural do educando ao desafio de uma situação-problema ${ }^{(3)}$.

O educador já não é mais o Que apenas educa, mas o Que eneuanto educa, é educado, em diálogo com o educando Que, ao ser educado, também educa. Ambos, assim se tornam sujeitos do processo em Que crescem juntos e em Que os argumentos de autoridade já não valem ${ }^{(4)}$.

Faz-se necessário dispor de uma aptidão geral para colocar e tratar os problemas e de princípios organizadores Que permitam ligar os saberes e lhes dar sentido, caracterizando uma cabeça bem-feita. Uma cabeça bem-feita é apta a organizar os conhecimentos e desta forma evitar sua acumulação estéril(").

As competências são construídas, através de um treinamento. Aprende-se fazendo, por meio de uma prática reflexiva, com um apoio, uma regulação e um acompanhamento individual( ${ }^{(16)}$.

Por outro lado, no Modelo Dialógico de Educação em Saúde, o indivíduo é reconhecido sujeito portador de um saber, Que embora distinto do saber técnico-científico não é deslegitimado pelos serviços. Em um modelo dialógico e participativo, todos, profissionais e usuários, atuam como iguais, ainda Que com papéis diferenciados ${ }^{(14)}$.

Os educandos devem ser vistos como agentes/co-produtores de um processo educativo. Possuem uma dupla dimensão no processo: são ao mesmo tempo objetos de trabalho dos agentes educativos e sujeitos de sua própria educação(II), tendo o educador problematizador, o papel de proporcionar, com os educandos, as condições em Que se dê a superação do conhecimento ${ }^{(1)}$.

A abordagem crítico-reflexiva torna-se pertinente, porque discute a ação educativa de forma inovadora, centrada no diálogo entre o educador e o educando ${ }^{(9)}$.

Em estudo realizado sobre educação popular em saúde no cuidado à criança desnutrida ${ }^{(10)}$, reconheceu-se Que as práticas educativas devem permitir aos indivíduos-sujeitos sociais, históricos e culturais, a oportunidade de conhecer e reconhecer a obtenção de destreza para a tomada de decisões, a fim de se obter uma melhor Qualidade de vida.

O modelo dialógico de Educação em Saúde tem sido associado a mudanças duradouras de hábitos e de comportamentos para a saúde, já Que é responsável pela construção de novos sentidos e significados individuais e coletivos sobre o processo saúde-doença-cuidado ${ }^{(14)}$.

A partir do momento em Que o indivíduo se descobre sujeito, deixando para traz a ignorância sobre a sua situação de oprimido, torna-se ator de práticas realmente libertadoras, comprometendose, com a sua transformação(4).

O educando deve ser reconhecido como sujeito portador de um saber sobre o processo saúde-doença-cuidado, sendo capaz de estabelecer uma interlocução dialógica com o serviço de saúde e de desenvolver uma análise crítica sobre a realidade e o 


\begin{tabular}{|c|c|}
\hline MODELO TRADICIONAL & MODELO DIALÓGICO \\
\hline Concepções & Concepções \\
\hline $\begin{array}{l}\text { Educação Bancária; } \\
\text { Transmissão de conhecimentos e ampliação de informações; } \\
\text { Cabeça bem-cheia; } \\
\text { Educandos: depósitos de conteúdos, são objetos do educador; } \\
\text { Não há estímulo para criação; } \\
\text { Seres passivos; } \\
\text { Educação verticalizada; } \\
\text { Considera-se a realidade do educador; } \\
\text { Pode não haver mudanças de hábitos e comportamentos; } \\
\text { Proporciona menor autonomia ao educando. }\end{array}$ & $\begin{array}{l}\text { Educação Problematizadora; } \\
\text { Construção de conhecimentos e competências; } \\
\text { Cabeça bem-feita; } \\
\text { Educandos: portadores de um saber, objeto de uma ação educativa e } \\
\text { sujeito da própria educação; } \\
\text { Aprende-se por meio de uma prática reflexiva; } \\
\text { Seres ativos; } \\
\text { Educação baseada no diálogo; } \\
\text { Considera-se a realidade do educando; } \\
\text { Mudanças duradouras de hábitos e comportamentos; } \\
\text { Proporciona maior autonomia ao educando. }\end{array}$ \\
\hline Vantagens & Vantagens \\
\hline $\begin{array}{l}\text { Proporciona à população o conhecimento produzido cientificamente; } \\
\text { Amplia informações e conhecimentos já existentes; } \\
\text { Produz aQuisição de conhecimento. }\end{array}$ & $\begin{array}{l}\text { Construção coletiva do conhecimento; } \\
\text { Proporciona ao educando visão crítica e reflexiva da realidade; } \\
\text { Capacita o educando para tomada de decisões. }\end{array}$ \\
\hline Desvantagens & Desvantagens \\
\hline $\begin{array}{l}\text { Formação de um indivíduo passivo, mero receptor de informações; } \\
\text { Não aplicação à realidade dos conteúdos ensinados; } \\
\text { Relação assimétrica entre educador e educando. }\end{array}$ & $\begin{array}{l}\text { Falta de conhecimento e capacitação de profissionais para aplicação } \\
\text { deste modelo. }\end{array}$ \\
\hline Aplicação & Aplicação \\
\hline $\begin{array}{l}\text { Projetos e capacitações de abrangência nacional; } \\
\text { Grupos com alto número de participantes, } \\
\text { Finalidade de sensibilização, sem necessariamente mudança de } \\
\text { prática. }\end{array}$ & $\begin{array}{l}\text { Projetos e capacitações de abrangência comunitária; } \\
\text { Grupos com menor número de participantes; } \\
\text { Atitudes de promoção de saúde; } \\
\text { Finalidade de produzir autonomia no indivíduo. }\end{array}$ \\
\hline
\end{tabular}

\section{Quadro 1. Síntese das concepções, vantagens, desvantagens e aplicações dos Modelos Tradicional e Dialógico de Educação.}

aperfeiçoamento das estratégias de enfrentamento e luta(11).

Torna-se importante Que se amplie a participação da pessoa cuidada como co-responsável pelas ações de saúde ${ }^{(9)}$. As práticas educativas devem permitir aos indivíduos-sujeitos sociais, históricos e culturais, a oportunidade de conhecer e reconhecer a obtenção de destreza para a tomada de decisões, na busca de uma melhor Qualidade de vida ${ }^{(10)}$.

As formas tradicionais de aprendizagem não desapareceram absolutamente ${ }^{(15)}$. Observou-se em um estudo com os profissionais de saúde da $\mathrm{ESF}^{(8)}$, Que estes não conseguem se despir do rigor do conhecimento científico considerado como verdade absoluta e única a ser inserida no conhecimento dos indivíduos, apesar de reconhecer a necessidade de considerar o conhecimento do paciente e sua cultura.

À luz da literatura, o Modelo Dialógico de Educação em Saúde apresenta como vantagens a construção coletiva do conhecimento, proporcionando aos indivíduos uma visão crítica-reflexiva da sua realidade, co-responsabilizando-o e capacitando-o para a tomada de decisões relativas à sua saúde. Apresenta como desvantagem a falta de conhecimento e capacitação dos profissionais para a aplicação deste modelo durante as atividades de Educação em Saúde.

A partir dos princípios do Modelo Dialógico de Educação em Saúde, entende-se Que o mesmo deva ser utilizado para trabalhar com grupos com menor número de participantes, em Que se faz necessária a mudança duradoura de comportamento e atitudes de promoção de saúde, em Que se busca a autonomia do indivíduo.

O Quadro l é uma síntese das concepções, vantagens, desvantagens e aplicações de cada modelo educativo.

\section{CONSIDERAÇÕES FINAIS}

O Modelo Tradicional de Educação em Saúde está fortemente enraizado nas práticas educativas realizadas pelos profissionais de saúde. Neste modelo, a transmissão do conhecimento técnicocientífico é privilegiada, sendo o educador o detentor do saber e o educando um depósito a ser preenchido pelo educador.

Entretanto, está bastante difundido o conhecimento crítico que Questiona a efetividade destas práticas. Contudo, pouco se tem feito para a transformação dessa realidade.

O Modelo Dialógico de Educação em Saúde propõe a construção do conhecimento, Que deve ser pautado no diálogo, em Que o educador e educando assumem papel ativo no processo de aprendizagem, através de uma abordagem crítico-reflexiva da realidade.

A aplicação dos princípios do Modelo Dialógico de Educação, nas práticas educativas em saúde, constitui um grande desafio, já Que muitos profissionais de saúde podem não ter conhecimento sobre esse modelo, outros não foram capacitados para aplicá-los a sua prática.

Durante as atividades de Educação em Saúde pode haver uma mistura dos dois modelos educativos: Tradicional e Dialógico, na tentativa de superação do primeiro, já Que o mesmo ainda apresentase fortemente inserido na prática profissional.

Há Que se considerar Que a aplicação destes dois modelos educativos deve ser feita de acordo com o contexto em que se está trabalhando, não sendo excludentes. 


\section{REFERÊNCIAS}

1. Morin E. A cabeça bem feita: repensar a reforma, reformar o pensamento. $7^{\text {a }}$ ed. Rio de Janeiro: Bertrand Brasil; 2002.

2. Cestari ME. Agir comunicativo, educação e conhecimento: uma aproximação ao pensamento de Habermas. Rev Bras Enferm 2002; 55(4): 430-3.

3. Bordenave JD, Pereira AM. Estratégias ensino-aprendizagem. $28^{a}$ ed. Petrópolis: Vozes; 2007.

4. Freire P. Pedagogia do oprimido. 46 ${ }^{\text {a }}$ ed. Rio de Janeiro: Paz e Terra; 2005.

5. Santos AS. Educação em saúde: reflexão e aplicabilidade em atenção primária á saúde. Online Braz I Nurs. [periódico on line] 2006 [citado em 2007 set 26]; 5(2). Disponível em: http:/ /www.objnursing.uff.br/index.php/nursing

6. Boesh AE, Monticelli M, Wosny AM, Heidmann IBS, Grisoti M. A interface necessária entre enfermagem, educação em Saúde e o conceito de cultura. Texto Contexto Enferm 2007; I6(2): 307-14.

7. Moura RF, Sousa RA. Educação em saúde reprodutiva: proposta ou realidade do Programa Saúde da Família? Cad Saúde Pública 2002; 18(6): 1809-11.

8. Bessen CB, Souza Netto M, Da Ros MA, Silva FW, Silva CG, Pires MF. A Estratégia Saúde da Família como Objeto de Educação em Saúde. Saúde e Sociedade 2007; 16(I): 57-68.
9. Alvim NAT, Ferreira MA. Perspectiva problematizadora da educação popular em Saúde e a enfermagem. Texto Contexto Enferm 2007; 16(2): 315-9.

10. Frota MA, Albuquerque CM, Linard AG. Educação popular em saúde no cuidado à criança desnutrida. Texto Contexto Enferm 2007; I6(2):246-53.

11. Toledo MM, Rodrigues SC, Chiesa AM. Educação em saúde no enfrentamento da hipertensão arterial: uma nova ótica para um velho problema. Texto Contexto Enferm 2007; 16(2): 233-8.

12. Freire P. Educação e mudanças. $30^{a}$. ed. Rio de Janeiro: Paz e Terra; 2007.

13. Rosa RB, Maffacciolli R, Nauderer TM, Pedro ENR. A educação em saúde no currículo de um curso de enfermagem: o aprender para educar. Rev Gaúcha Enferm 2006; 27(2): 185-92.

14. Alves VS. A health education model for the Family Health Program: towards comprehensive health care and model reorientation. Interface - Comunic Saúde, Educ 2005; 9(16): $39-52$.

15. Perrenoud P. Pedagogia diferenciada: das intenções à ação. Porto Alegre: Artes Médicas Sul; 2000.

16- Perrenoud P. Escola e cidadania: o papel da escola na formação para a democracia. Porto Alegre: Artmed, 2005. 